\title{
Miniaturized tube fixed plug drawing: Determination of the friction coefficients and drawing limit of 316 LVM stainless steel
}

\author{
N. Chobaut ${ }^{\mathrm{a}}$, J-M. Drezet ${ }^{\mathrm{b}, *}$, S. Mischler ${ }^{\mathrm{b}}$, V. Nguyen $^{\mathrm{b}}$, B. De Marco ${ }^{\mathrm{c}}$, S. Dobler ${ }^{\mathrm{c}}$, E. Rosset $^{\mathrm{a}}$ \\ a University of Applied Sciences and Arts Western Switzerland (HES-SO), Hepia, 1202 Geneva, Switzerland \\ ${ }^{\mathrm{b}}$ Swiss Federal Institute of Technology (EPFL), Tribology and Interfacial Chemistry Group, 1015 Lausanne, Switzerland \\ ${ }^{c}$ Swiss-Tube LN Industries SA, 1424 Champagne, Switzerland
}

\section{A R T I C L E I N F O}

\section{Keywords:}

Tube fixed-plug drawing

Friction

316 LVM

Johnson-Cook

Stribeck

Stick-slip

\begin{abstract}
A B S T R A C T
Tube drawing with a fixed plug is investigated experimentally and numerically in order to optimise an industrial pass sequence. Tube drawings are performed on a laboratory drawing bench equipped with force, displacement and temperature sensors. The drawing limit of 316 LVM stainless steel (SS) tubes is determined by varying the plug position and the effect of lubricant is discussed. The numerical model relies on the precise die geometry measured using a contact method and on the mechanical behaviour of SS 316 LVM characterised by tensile tests between $20^{\circ} \mathrm{C}$ and $200^{\circ} \mathrm{C}$ on annealed tubes. The friction coefficients between tube and die and tube and plug are determined by FE modelling by comparing measured and simulated plug, die and drawing forces. The use of a solid lubricant together with the lubricating oil prevents stick and slip and lowers the friction coefficients. Friction is further decreased by preheating the die. The identified friction coefficients are discussed in terms of the classic Stribeck friction curves and lubrication is found to be in the hydrodynamic regime.
\end{abstract}

\section{Introduction}

Stainless steel (SS) is widely used for engineering applications where high formability, environmental resistance and specific mechanical properties are required. 316 LVM (Low carbon Vacuum Melted) seamless tubes in particular are used in the automotive, watch and medical industries where precise dimensions and good surface finish are required (Poncin and Proft, 2004). Seamless tubes are less prone to grain boundary stress corrosion compared to welded tubes due to impurities segregation in the welding seam. Starting from seamless pipes, tubes are cold drawn through dies. In the trend towards miniaturisation (tubes with smaller diameter and thinner wall thickness) a large number of passes are often required to reach the final tube dimensions. While the first passes are usually performed with a mandrel to reach high section reductions, the final passes are achieved with a plug to lower inner surface roughness (Yoshida and Furuya, 2004).

After drawing, the material is work-hardened and needs to be annealed to recover its ductility for subsequent passes. Industrially, multipass drawing without interpass annealing is often performed to decrease the drawing force per pass (Fang et al., 2013). One way to decrease the number of passes is to increase the section reduction per pass as shown by Karnezis and Farrugia (1998) who replaced two-pass schedules with single-pass schedules. To avoid fracture occurring at the die exit, the drawing stress applied to the drawn section at the die exit must remain within a safety margin below the ultimate tensile stress of the drawn material. The axial stress in the drawn tube is therefore the main limitation for drawing as shown by Béland et al. (2011). Bui et al. (2011) determined the drawing limit of AA6063 tube using a $5^{\circ}$ halfangle conical mandrel. The same approach using a $0.053^{\circ}$ half-angle conical mandrel was applied for L605 cobalt-chromium tubes (Linardon et al., 2014). In her PhD dissertation, Linardon (2014) performed similar measurements on $316 \mathrm{LVM}$ tubes and found a section reduction at fracture of $62.9 \%$. Palengat et al. (2013) performed cylindrical mandrel drawings of $316 \mathrm{LVM}$ tubes and obtained a drawing stress of $750 \mathrm{MPa}$ at $55 \%$ section reduction. This excellent ductility of face-centered cubic austenitic steels is not only due to their low stacking fault energy (Padilha et al., 2003) but also due to the loading path during drawing with an initial compression, which increases the tensile fracture limit.

On the numerical side, Linardon and Palengat found, by Finite Element Modelling (FEM), Coulomb friction coefficients lower than 0.1 but did not give information on lubrication. Furthermore, their works led to the conclusion that the temperature increase during drawing needs to be considered in the material model, for example in Furushima and Manabe (2007).

The above-mentioned works are adapted here for tube fixed-plug drawing, which differs from mandrel drawing by the fact that the plug

\footnotetext{
* Corresponding author.

E-mail address: jean-marie.drezet@epfl.ch (J.-M. Drezet).
} 
is fixed. The drawing stress vs. section reduction curves are determined by varying the plug position for different thermal and lubricating conditions. Numerically, the influence of temperature is taken into account through the temperature-dependent mechanical properties of 316 LVM.

The present work associates precise measurements (tools geometry, material behaviour, forces on tools and tube, temperature and lubricating film thickness) with FEM calculations to determine the unknown friction coefficients. The identified coefficients are discussed in terms of the classic Stribeck friction curves to determine the lubrication regime on the tube-die contact.

\section{Experimental procedure}

\subsection{Materials}

316 LVM stainless steel tubes with the chemical composition given in Table 1 are provided by Swiss-Tube after ca. 10 min annealing at $1020^{\circ} \mathrm{C}$ in a continuous furnace under hydrogen as protective gas. Tube nominal dimensions are $3.78 \mathrm{OD} \times 3.50 \mathrm{ID} \times 0.140 \mathrm{~T} \mathrm{~mm}$ where $\mathrm{OD}$ is the tube outer diameter, ID is the inner diameter and $\mathrm{T}$ is the tube thickness.

The microstructure is fully austenitic with equiaxed grains of average size of $16-19 \mu \mathrm{m}$ (ASTM grain nr. 8.5-9) before drawing as shown in Fig. 1-a (longitudinal direction) and Fig. 1-b (transverse direction). The as-drawn microstructures exhibit deformation bands preferentially oriented in the drawing direction, shown in Fig. 1-c. Since plastic deformation occurs without volume change and there is an absence of dynamic recrystallisation during cold drawing, grains elongate in the drawing direction. For instance, an aspect ratio of ca. 2 (grains of average size $11 \mu \mathrm{m} \times 23 \mu \mathrm{m}$ ) is seen at $47 \%$ section reduction (Fig. 1-d). After drawing, grain size remains uniform throughout the thickness. The initial grain size of $16-19 \mu \mathrm{m}$ is recovered after the annealing step.

The tools (die and plugs) are made of Extramet EMT 210 tungsten carbide (WC) with an average grain size lower than $0.8 \mu \mathrm{m}$. After machining and polishing, the roughness of the tools' contact zones are ca. $0.7 \mu \mathrm{m}$ for the die and ca. $0.03 \mu \mathrm{m}$ for the plugs according to optical roughness measurements (Keyence VK-X250).

Two commercial lubricating oils with different viscosities (Fig. 2) were used for drawing. Viscosity measurements were performed on a TA instruments DHR-2 rheometer. A shear rate ramp from 0.1 to 100 $\mathrm{s}^{-1}$ was applied after the temperature was maintained constant for $5 \mathrm{~min}$. Both lubricants are liquid and display Newtonian behaviour in the tested shear rate and temperature ranges at atmospheric pressure. While lubricant A (LA) is 10 times more viscous than lubricant B (LB) at $27^{\circ} \mathrm{C}$, their dynamic viscosity is almost identical at $90^{\circ} \mathrm{C}$. Although LA features a higher thermal stability than LB, both lubricants produce smoke above ca. $150^{\circ} \mathrm{C}$. LA, being highly chlorinated, is denser than chlorine-free lubricant LB $\left(1.29\right.$ vs $0.99 \mathrm{~g} / \mathrm{cm}^{3}$ at $\left.23^{\circ} \mathrm{C}\right)$.

\subsection{Tensile tests}

In order to be as close as possible to the industrial conditions, tensile tests on $3.78 \mathrm{OD} \times 3.50 \mathrm{ID} \times 0.140 \mathrm{~T} \mathrm{~mm}$ tubes taken from the production line in annealed state were performed at different strain rates and temperatures. An Instron 1431 hydraulic tensile machine was chosen in combination with a short specimen length in order to reach strain rates as high as possible since strain rate during drawing reaches several tens of $\mathrm{s}^{-1}$ at $40 \mathrm{~mm} / \mathrm{s}$ and several hundreds of $\mathrm{s}^{-1}$ at $300 \mathrm{~mm} / \mathrm{s}$. $3.48 \mathrm{~mm}$ diameter pins are inserted at both tube extremities in order to avoid tube crushing in the V-shaped grips as suggested by Linardon. Axial strain is measured using a Sandner EXA 20-50 extensometer (error of $<0.5 \%$ ) with a gauge length of ca. $16 \mathrm{~mm}$ in agreement with the ASTM A370-16 standard recommending a value of at least 4 times the outer tube diameter. Tensile loads are performed at constant displacement rates. Strain rate jumps are performed in order to characterise the strain-rate sensitivity. A $10 \mathrm{kN}$ load cell is used to record the force. Besides tests at room temperature, tests were performed at $100{ }^{\circ} \mathrm{C}$ and $200{ }^{\circ} \mathrm{C}$ in a Shimatzu TCE-N300 furnace.

\subsection{Tube fixed-plug drawings}

A home-made 6-meter-long drawing bench was used for tube fixedplug drawings. It is equipped with two force sensors, two heating resistances and three thermocouples (Fig. 3).

During drawing, the tube is pulled into the die by a conveyor. As the plug is dragged into the die due to friction, it is held by a rod fixed to the bench. Although the plug position is fixed during drawing, it can be modified by adjusting the rod length. This adjustment is made either before a new drawing or after interrupting a drawing in order to obtain a tube with different section reductions. This, in combination with the conical shape of the plug, allows increasing the pass severity by positioning the plug deeper into the die.

Forces are measured by piezo-electric sensors chosen for their high accuracy and their high rigidity, ideal for dynamic measurements. The drawing force, $F_{\text {draw }}$, and the reaction force on the plug, $F_{p l u g}$, were measured using 9311B Kistler sensors. Plug, die and conveyor were carefully aligned by laser. Force equilibrium was therefore used to compute the reaction force on the die, $F_{\text {die }}: F_{\text {die }}=F_{\text {draw }}-F_{\text {plug. }}$. The measuring chain comprises high-insulation cables and a charge amplifier. The conveyor position is measured using a magnetic encoder (GCA5 Baumer). A LabVIEW-based data acquisition system (National Instruments USB6259) is used on a laptop to record forces and conveyor position at a sampling rate of $5 \mathrm{kHz}$ with an averaging window of 100 samples.

Three thermocouples are used to estimate the tube temperature in the bearing zone, $T_{\text {tube }}$, which cannot be measured directly. The die is equipped with two type-K thermocouples as shown in Fig. 3. These two thermocouples are positioned in $0.8 \mathrm{~mm}$ diameter and $2 \mathrm{~mm}$ depth holes machined by EDM at $180^{\circ}$ from each other. Contrary to the work of Haddi et al. (2011), the holes are drilled perpendicular to the thermal gradient following the work of Chobaut et al. (2015). The position of TC1 and TC2 from the die axis is $r_{1}=2.8 \mathrm{~mm}$ and $r_{2}=3.6 \mathrm{~mm}$ respectively. The surface temperature, $T_{s}$, is estimated assuming a constant thermal gradient:

$T_{S}=T_{1}-\frac{T_{1}-T_{2}}{r_{1}-r_{2}}\left[r_{1}-r_{d i e}\right]$

where $T_{1}$ and $T_{2}$ are the temperatures measured by TC1 and TC2 respectively and $r_{d i e}$ is the die radius at the depth of TC1. Eq. 1 assumes that temperature is distributed linearly along the radial direction, which may lead to large deviation (Linardon, 2014). Therefore, $T_{s}$ is considered as a lower bound of $T_{\text {tube }}$ and another thermocouple is used complementarily in order to improve the estimation of the tube temperature. This thermocouple is an Omega $88227 \mathrm{~K}$ contact thermocouple placed at the die exit (Fig. 3) at about $20 \mathrm{~mm}$ from the tube-die contact zone. Due to convection loss, it gives a temperature, $T C_{\text {contact }}$,

Table 1

Chemical composition of 316 LVM stainless steel (in wt. \%).

\begin{tabular}{|c|c|c|c|c|c|c|c|c|c|c|}
\hline Elements & $\mathrm{Si}$ & $\mathrm{Cu}$ & $\mathrm{Mn}$ & $\mathrm{C}$ & $\mathrm{Cr}$ & $\mathrm{Ni}$ & Mo & $\mathrm{N}$ & $\mathrm{P}$ & $S$ \\
\hline wt. \% & 0.52 & 0.044 & 1.63 & 0.017 & 17.47 & 14.35 & 2.74 & 0.064 & 0.016 & $\leq 0.001$ \\
\hline
\end{tabular}



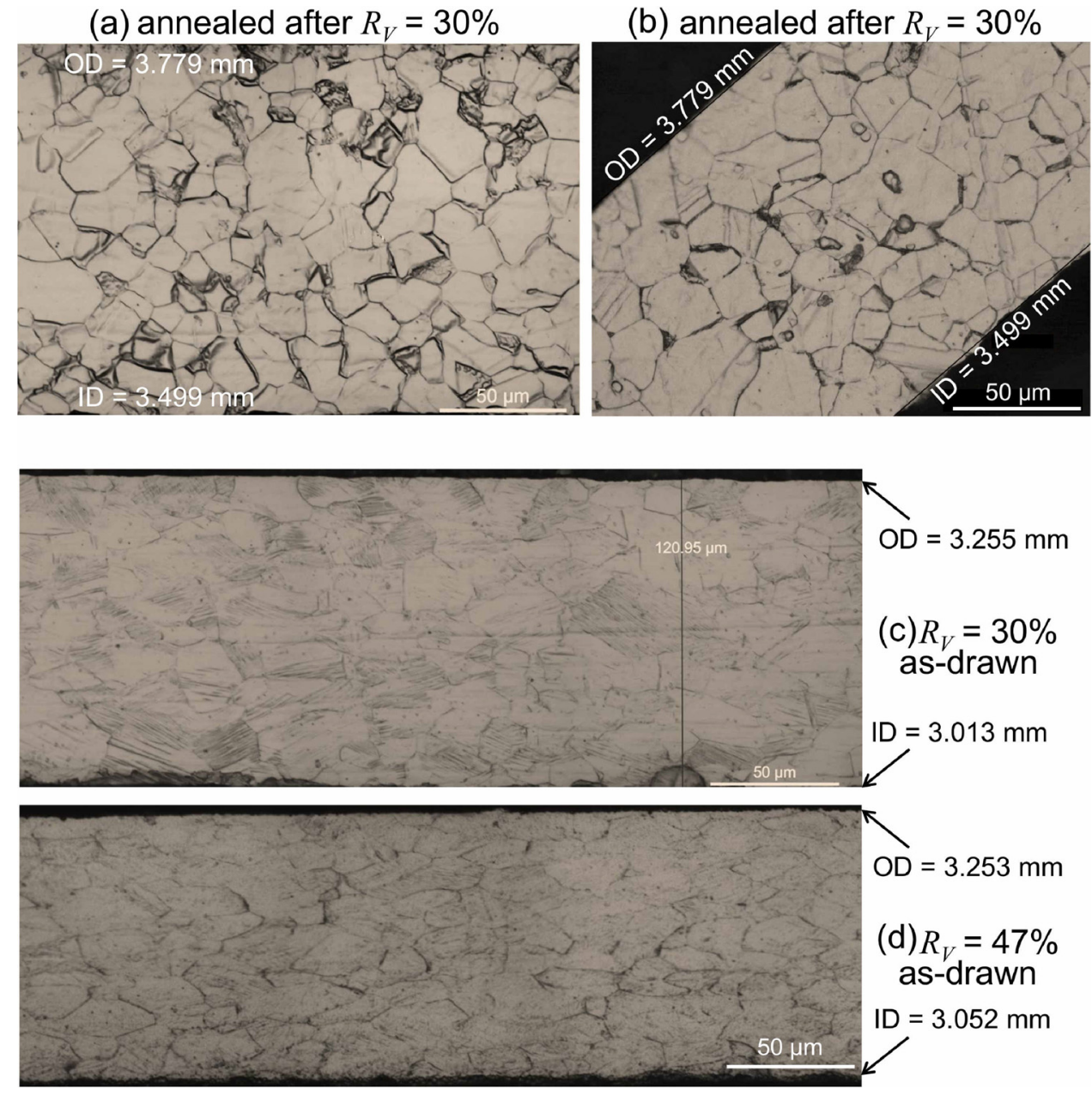

Fig. 1. Optical micrographs before drawing in longitudinal (a) and transverse (b) directions and after drawing at 30\% (c) and 47\% section reduction (d) in longitudinal direction. The longitudinal (i.e. drawing) direction is horizontal in (a, c and d).

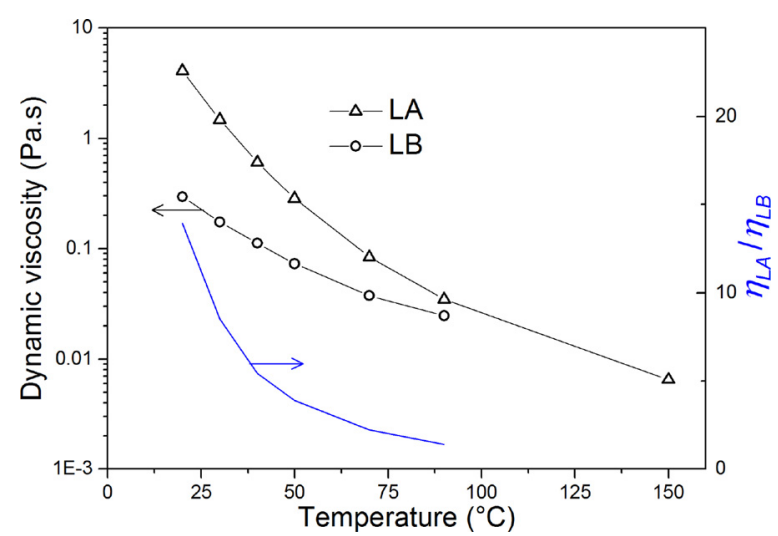

Fig. 2. Temperature-dynamic viscosity diagram at 1 bar of LA and LB used in this work.

considered also as a lower bound of $T_{\text {tube }}$. The tube temperature was therefore considered at least equal to the maximal value between $T_{s}$ and $T C_{\text {contact }}$. Thermal measurements are performed at $10 \mathrm{~Hz}$ using a NetDaq Networked Data Acquisition Unit together with the NetDAQ Logger software.

The tools' dimensions were measured at $20{ }^{\circ} \mathrm{C}$ and $50 \%$ relative air humidity using a Werth VideoCheck machine in sensor mode with a rigid stylet equipped with a $2 \mathrm{~mm}$ diameter sapphire ball (error of $\pm 1.8 \mu \mathrm{m}$ determined on a standard ring).
Prior to drawing, a ca. $10 \mathrm{~mm}$ long tip (3.10 mm OD) was cold forged by rotary swaging in order to insert the tube into the die. The liquid lubricating oil (LA or LB) was applied generously by hand on the plug and on the tube outer surface and a pressurised nozzle was used to fill the tube. A water-soluble polymer-based solid lubricant (SL) containing about 3.5 at $\%$ of $\mathrm{Na}$ and 2.3 at $\%$ of $\mathrm{Cl}$ according to XPS measurements was applied on the tube inner and outer surfaces. This solid lubricant used in conjunction with the liquid lubricating oil improved lubrication thus allowing higher section reductions. An accumulation of lubricant at the die entry was observed during drawing. This is due to the squeezing out of the lubricant. After drawing, the tubes were visually inspected to check the absence of surface defects.

In order to determine the tube dimensions before and after drawing, ca. $150 \mathrm{~mm}$ long samples are cut and cleaned. The outer diameter (OD) is measured with a laser (error of $\pm 1 \mu \mathrm{m}$ ) at 6 different positions on the sample. The average cross-sectional area, $S$, is calculated from the sample mass, $m$, (error of $\pm 2 \mathrm{mg}$ ) and length, $L$, (error of $\pm 0.02 \mathrm{~mm}$ ). The inner diameter (ID) and the thickness (T) are derived from OD and $S$ assuming perfect cylinders. From these measurements, the true section reduction, $R_{V}$, is calculated as:

$R_{V}=\ln \left(\frac{S_{\text {in }}}{S_{\text {out }}}\right)=\ln \left(\frac{m_{\text {in }} L_{\text {out }}}{m_{\text {out }} L_{\text {in }}}\right)$

where the subscripts in and out stand for inlet (before drawing) and outlet (after drawing) tubes.

The roughness of the cleaned outer and inner sample surfaces was measured using a Keyence VK-X250 3D laser scanning confocal 


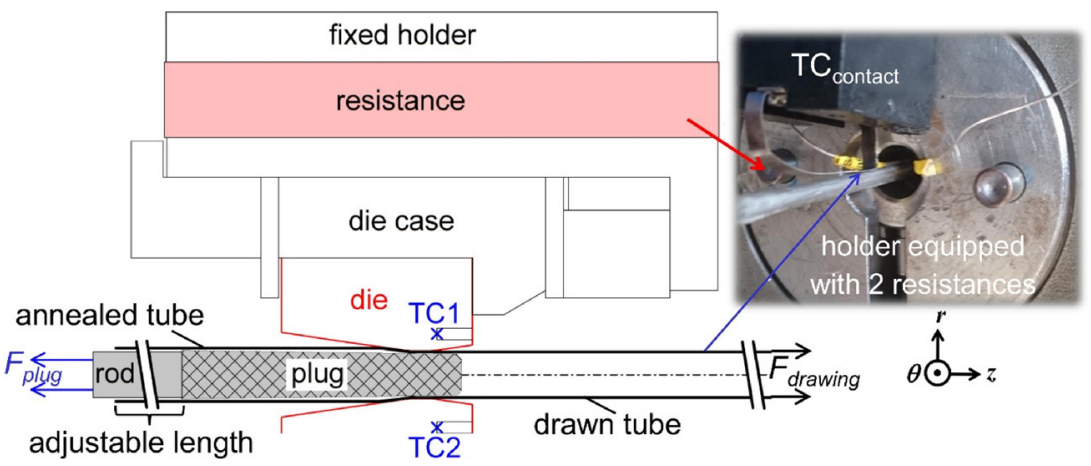

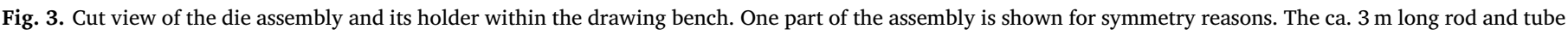
are cut for the sake of clarity.

microscope with $0.25 \mu \mathrm{m}$ spatial resolution and $0.0005 \mu \mathrm{m}$ precision in height.

\subsection{Estimation of lubricant film thickness after drawing}

The thickness of the carbon-based lubricant layer was measured on uncleaned as-drawn samples. X-ray photoelectron spectroscopy (XPS) was used for characterisation of near-surface chemical composition using a PHI VersaProbe II scanning XPS microprobe from Physical Instruments AG. The device used a monochromatic $\mathrm{Al} \mathrm{K \alpha} \mathrm{X}$-ray source with $25.2 \mathrm{~W}$ power and a beam size of $100 \mu \mathrm{m}$. Depth profiling was performed at $46.95 \mathrm{eV}$ pass energy using Argon ion sputtering over an area of $1 \mathrm{~mm} \times 1 \mathrm{~mm}$. For chemical analysis, the spectra were shifted so that the C1s C-C peak is at $284.8 \mathrm{eV}$. Carbon, iron, oxygen, and chlorine composition was of particular interest. For carbon, the C1s peak was analysed around $285 \mathrm{eV}$. For iron, the Fe2p peak was analysed around $705 \mathrm{eV}$ to $725 \mathrm{eV}$. For oxygen, the $01 \mathrm{~s}$ peak was analysed around $533 \mathrm{eV}$. For chlorine, the $\mathrm{Cl} 2 \mathrm{p}$ peak is analysed around $200 \mathrm{eV}$.

\section{Modelling}

\subsection{Constitutive equation}

To fit the measured stress-strain curves, a phenomenological law with multiplicative hardening (modified Johnson-Cook model) is chosen as an alternative to more complex physically-based laws (Bui et al., 2013). The uniaxial tensile load at constant temperature is defined by Palengat et al. (2013):

$\sigma_{V}=\left(A+B p^{n}\right)\left[1+C \ln \left(\dot{p} / \dot{p}_{0}\right)\right]$ with $\dot{p}=\mid \dot{\varepsilon}^{i n \mid}$ and $p=\int \dot{p} \mathrm{~d} t$

where $\sigma_{V}$ is the true axial flow stress, $\dot{\varepsilon}^{i n}$ is the inelastic strain rate and $p$ is the inelastic deformation. In Eq. (3), $A$ is the yield strength at $0 \%$ strain offset, $B$ and $n$ are hardening parameters, $C$ is the strain-rate sensitivity and $\dot{p}_{0}$ is the reference plastic strain rate. The parameters $(A, B, n, C)$ are temperature-dependent. Following the works of Palengat et al. (2013) and Linardon et al. (2014), the modified Johnson-Cook law is chosen because its parameters are easier to identify than the parameters of additive laws (Lemaitre and Chaboche, 1988), it is implemented in Abaqus and parameters for a $316 \mathrm{LVM}$ stainless steel are available at $20^{\circ} \mathrm{C}(A=287 \mathrm{MPa}$, $B=1265 \mathrm{MPa}, n=0.664, C=0.021$ ) for comparison (Linardon, 2014).

\subsection{FE model of drawing}

An axisymmetric finite element (FE) model is built in Abaqus/ Standard to simulate fixed-plug drawing as illustrated in Fig. 4. A tube $(3.78 \mathrm{OD} \times 3.50 \mathrm{ID} \times 0.140 \mathrm{~T} \mathrm{~mm})$ is meshed over a length of $10 \mathrm{~mm}$ using four-node bilinear axisymmetric quadrilateral elements (CAX4). 9 elements are used through the tube thickness with a size of $10 \mu \mathrm{m}$ along the tube axis.

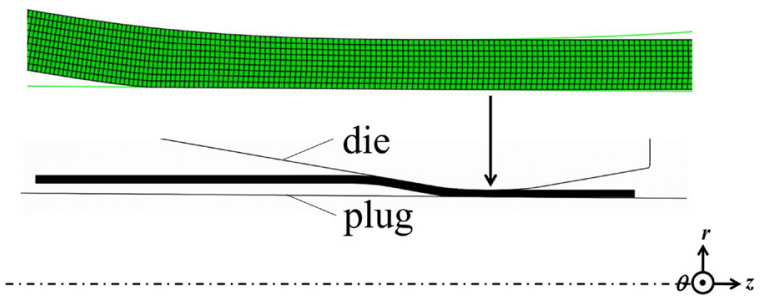

Fig. 4. Axisymmetric model of tube fixed-plug drawing. Only the contours of the tools (die and plug2) defined by analytical surfaces are visible.

The numerical model relies on the accurate die geometry measured using a contact method and on the mechanical behaviour of SS 316 LVM characterised by tensile tests between 20 and $200^{\circ} \mathrm{C}$ on annealed tubes.

The axisymmetric and isothermal FEM model with rigid tools features the following assumptions:

- Considering the large elastic modulus of the WC tools, they are assumed rigid and are therefore defined by analytical surfaces in Abaqus.

- Constant drawing speed corresponding to steady state.

- A given temperature is imposed to the whole tube, i.e. heat flow is not calculated. This assumption is justified by the fact that the tube heats up rapidly at the beginning of drawing by deformation heat dissipated throughout its volume and by friction heat dissipated on its surfaces.

- The elastic properties are taken at $20^{\circ} \mathrm{C}$ (Young's modulus of $192 \mathrm{GPa}$ and Poisson coefficient of 0.29 according to Linardon (2014)) after checking that their temperature-dependency has a negligible effect on the predicted forces.

- As temperature is uniform, mechanical properties with isotropic hardening (Johnson-Cook model) are also uniform.

- Accumulation of plastic deformation with no dynamic recrystallization.

- Uniform Coulomb friction coefficients on both tools, plug and die.

The friction coefficients between tube and plug, $\mu_{\text {plug }}$, and tube and die, $\mu_{\text {die }}$, are determined by FE modelling by comparing measured and simulated axial plug and die forces for a given section reduction. This identification procedure is done for each pass by varying the axial position of the conical plug in the FE model.

\section{Results and discussion}

\subsection{Thermo-mechanical behaviour}

The tensile curves at $20^{\circ} \mathrm{C}, 100{ }^{\circ} \mathrm{C}$ and $200{ }^{\circ} \mathrm{C}$ are shown in Fig. 5-a. Flow stress increases with decreasing temperature and increasing strain 


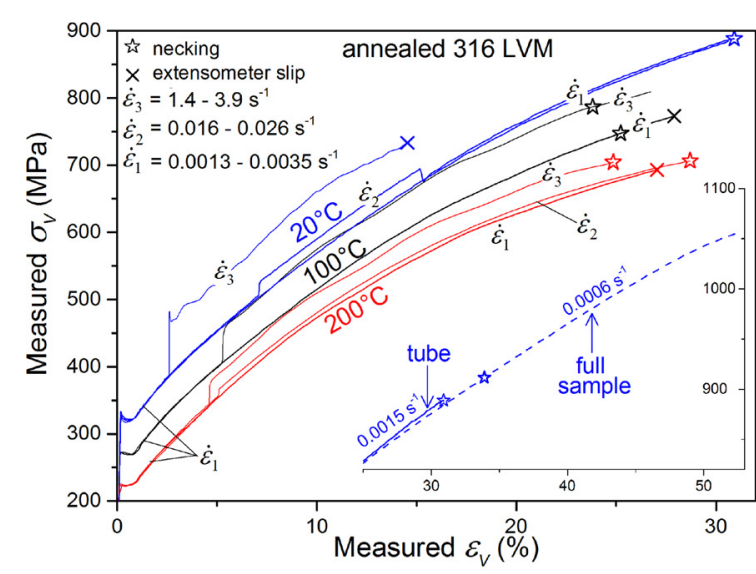

(a)

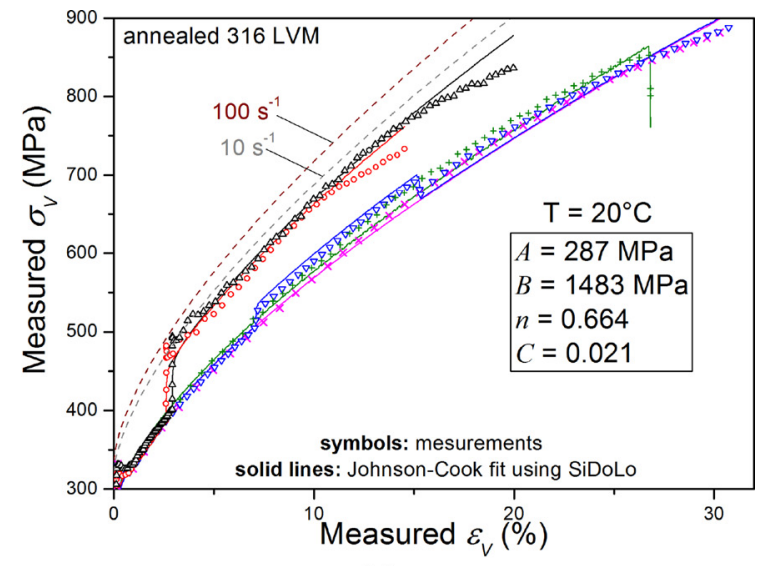

(b)

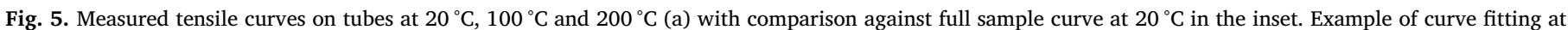
$20^{\circ} \mathrm{C}$ using SiDoLo (b).

rate as this is the case for austenitic stainless steels in the tested temperature and strain rate range (Hong and Lee, 2004). However, contrary to most other metals, the ductility of austenitic SS decreases when temperature increases from $20^{\circ} \mathrm{C}$ to $200{ }^{\circ} \mathrm{C}$ as shown by Byun et al. (2004) for annealed 316 SS and by Hong and Lee (2004) for a 17\% prestrained $316 \mathrm{~L}$ SS. This is shown for 316 LVM in Fig. 5-a where the stars indicate the onset of necking according to Considere's criterion for plastic instability. Due to the present strain rate limitation of ca. $4 \mathrm{~s}^{-1}$, Hopkinson bar tests typically used to feed material models for crash simulations should be considered, seen for instance in Bui-Van et al. (2009). Such tests performed on a SS 316 L (Albertini et al., 2014) at $20^{\circ} \mathrm{C}$ show that necking occurs at lower strains for higher strain rates as also observed in Fig. 5-a.

High deformations measurements on tubular tensile specimens being limited by extensometer slip (crosses in Fig. 5-a) strain measurements were performed by stereo digital image correlation on full tensile samples cut in the thickness of $25.0 \mathrm{OD} \times 20.0 \mathrm{ID} \times 2.5 \mathrm{~T} \mathrm{~mm}$ annealed 316 LVM seamless pipes corresponding to the material at Swiss-Tube before any pass. The tensile curve at $20^{\circ} \mathrm{C}$ and $0.0006 \mathrm{~s}^{-1}$ (see inset in Fig. 5-a) is consistent with the curve obtained on tubes and shows that fracture occurs at around $53 \%$ true strain at a true stress of about $1050 \mathrm{MPa}$.

The experimental stress-strain curves in Fig. 5-a are fed into a dedicated optimisation software (SiDoLo) developed by Pilvin and Cailletaud (1994) to determine the four model parameters $(A, B, n, C)$ giving the best fit as shown exemplarily in Fig. 5-b. Similarly to the work of Linardon (2014), $\dot{p}_{0}=0.03 / \mathrm{s}$ was chosen in Eq 3-1 for the sake of comparison. At $20^{\circ} \mathrm{C}$, the obtained parameters (see inset in Fig. 5-b) are identical to the ones of Linardon based on tube tensile tests at 0.03 , 3 and $9 \mathrm{~s}^{-1}$, except $B$ equal to $1265 \mathrm{MPa}$ in Linardon's work. This difference comes from the different chemical composition of the two 316 LVM alloys and their initial grain size $(32 \mu \mathrm{m}$ for Linardon versus $16-19 \mu \mathrm{m}$ in this work). The yield strength $A$ and the strain-rate sensitivity $C$ decrease with increasing temperature (Fig. 6).

The work hardening parameters $B$ and $n$ also decrease with increasing temperature. These two parameters having an antagonistic effect on the work hardening term B. $p^{n}$ (a decrease of $n<1$ leads to an increase of this term for $p<1$ ). It was checked that the work hardening term decreases with increasing temperature. The same trend, attributed to a maximal accumulation of dislocations at low temperature and an increase of their annihilation probability at high temperature, was found for a 17\% pre-strained 316 L SS (Hong and Lee, 2004).

For FE drawing simulations, the temperature-dependent parameters ( $A$, $B, n, C)$ are interpolated linearly as a function of temperature and treated as uniform material properties (applied throughout the whole tube).

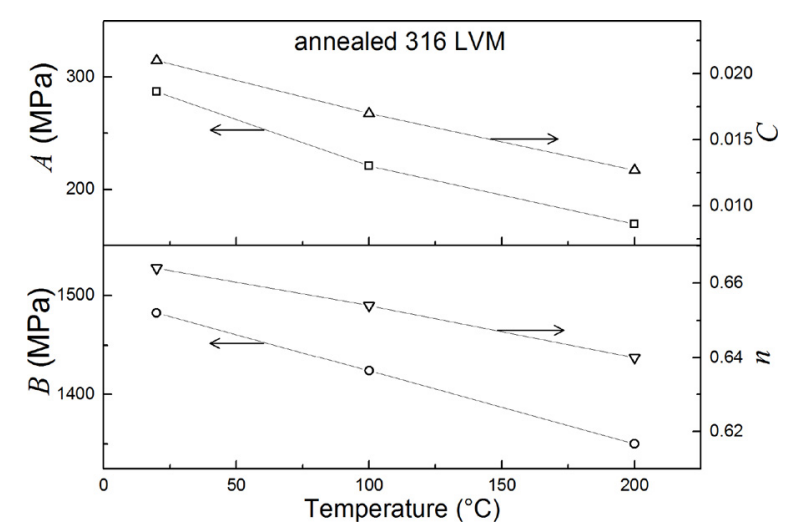

Fig. 6. Parameters of the Johnson-Cook law as a function of temperature. Solid lines are drawn to guide the eye.

\subsection{Tools geometry}

The die and plug's geometries are shown in Fig. 7-a and b respectively where the coloured surface represents the difference between measurements (dots) and their fits (conical or cylindrical). This difference is lower than $0.1 \%$ of the die diameter $(\varnothing 3.253 \mathrm{~mm})$ and about $0.5 \%$ of the average plug diameter. Therefore, both tools are considered axisymmetric and their average profiles are taken as input for the FE model.

The die (Fig. 7-a) features a ca. $9.8^{\circ}$ half-angle reduction cone whose goal is to reduce the tube diameter. The tube thickness is controlled by the relative position between the die bearing zone and the plug. The bearing zone can be approximated by a $0.26 \mathrm{~mm}$ high cylinder with a diameter of $3.253 \mathrm{~mm}$. The mean curvature radius between the reduction cone and the bearing zone is ca. $6.562 \mathrm{~mm}$. These values of die half-angle and curvature radius were chosen following the work of Béland et al. (2011) in order to minimise the pulling force without compromising lifespan.

Two plugs, whose purpose is to control the tube ID, were used (Fig. 7-b). Plug1 is typical of production with an average diameter of $3 \mathrm{~mm}$ and a maximal diameter of $3.09 \mathrm{~mm}$. Plug2 is conical with a halfangle of ca. $0.40^{\circ}$ over $35 \mathrm{~mm}$ and a maximal diameter of $3.43 \mathrm{~mm}$, thus allowing to increase pass severity up to fracture.

\subsection{Experimental drawing results}

Passes were performed at different section reductions and different 


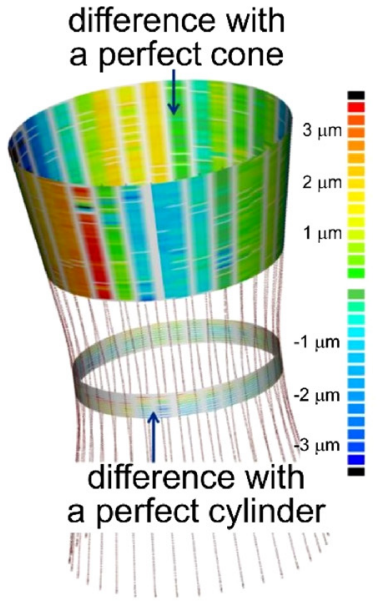

(a)

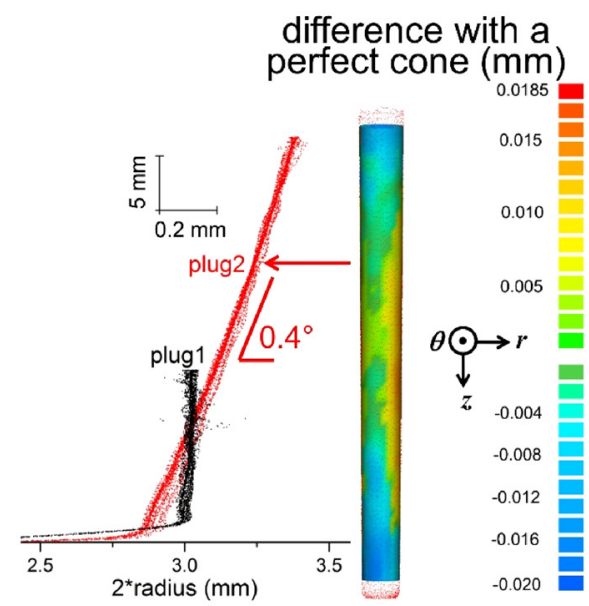

(b)

Fig. 7. 3D measurements of the die (a) and the plug's (b) geometries.

drawing conditions. Three parameters (lubrication, drawing speed and initial die temperature, $T_{\text {die }}$ ) were varied as shown in Table 2.

\subsubsection{Occurrence of stick-slip}

Drawing using LA at $v_{1}$ and $T_{\text {die }}=\mathrm{RT}+45^{\circ} \mathrm{C}$ led to stick-slip known as "chatter" at $R_{V}>25 \%$ as indicated in Table 2 . This corresponds to an intermittent motion of the tube relative to the tools (Cook, 1980) associated with stick-slip spikes on the force evolution as shown in Fig. 8a after ca. $3 \mathrm{~s}$ of smooth sliding. This phenomenon is undesirable due to slight dimensional variations and visible marking on the drawn tube (see inset of Fig. 8-a). Drawing using LA at $v_{1}$ and $R_{V}=30 \%$ was achieved up to $T_{\text {die }}=110^{\circ} \mathrm{C}$ without chatter by using plug1 instead of plug2 (Fig. 8-b). This is due to the larger interspace available for lubricant feeding of the tube-plug contact when the plug maximal diameter is decreased. Lubricant viscosity also plays an important role in the occurrence of chatter as evidenced in Fig. 8-b showing stick-slip at $T_{\text {die }}=127^{\circ} \mathrm{C}$ using LA at $v_{1}$ and $R_{V}=30 \%$ with plug1. Drawings in similar conditions $\left(v_{1}, R_{V}=30 \%\right.$, plug1) but using LB instead of LA led to chatter at $T_{\text {die }} \geq 55^{\circ} \mathrm{C}$. The use plug2 instead plug1 led to systematic chatter using LB.

The fact that the die force remains fairly constant during chatter indicates that sticking occurs mainly between tube and plug because of lubricant starvation inside the tube by the collapse of the thick-film of lubricant due to a too low viscosity. Indeed, Lee et al. (2002) found that full-film lubrication collapses with decreasing viscosity. While Cook (1980) demonstrated the advantage of using a "plastic plug lubricant" instead of oil to reduce chatter, we found here that chatter never occurred when using solid lubricant together with LA or LB. Besides increasing lubricant viscosity, chatter is prevented by decreasing plug maximal diameter (using plug1 instead of plug2) and decreasing pass severity.

\subsubsection{Estimation of tube temperature}

The tube temperature in the bearing zone, $T_{\text {tube }}$, is an important input parameter for the modelling. It is estimated using the

Table 2

Overview of tested drawing conditions with plug2 and corresponding achieved section reduction range without fracture.

\begin{tabular}{cllll}
\hline & speed & LA & LA + SL & LB + SL \\
\hline die at & $v_{1}=40 \mathrm{~mm} / \mathrm{s}$ & $21-37 \%$ & $17-47 \%$ & $18-53 \%$ \\
$\mathrm{RT}=23 \pm 3{ }^{\circ} \mathrm{C}$ & $v_{7}=300 \mathrm{~mm} / \mathrm{s}$ & $22-36 \%$ & $41-47 \%$ & $23-53 \%$ \\
die at RT $+45^{\circ} \mathrm{C}$ & $v_{1}=40 \mathrm{~mm} / \mathrm{s}$ & chatter at $R_{V}>25 \%$ & $22-63 \%$ & $22-61 \%$ \\
\hline
\end{tabular}

thermocouples presented in section 2.3. A typical temperature evolution at $v_{1}$ and $T_{\text {die }}=\mathrm{RT}$ is shown in Fig. 9-a. Temperature increases rapidly during the first $10-20 \mathrm{~s}$ before reaching a quasi-steady-state value. The temperature drop at $40 \mathrm{~s}$ when the drawing speed was suddenly decreased shows the high sensibility of the measurements.

The fact that $T_{s}$ is lower than $T C_{\text {contact }}$ when drawing at $T_{\text {die }}=\mathrm{RT}$ is attributed to the high thermal inertia of the die assembly compared to the tube, which reaches a steady-state value almost instantaneously as found by thermo-mechanical simulations. Therefore, $T_{s}$ must be considered as a lower bound of $T_{\text {tube }}$. When drawing at $v_{7}$ (Fig. 9-b) the thermal steady state is not reached and $T C_{\text {contact }}$ (and therefore $T_{\text {tube }}$ ) exceeds $120^{\circ} \mathrm{C}$, which is consistent with the observed smoke indicating a lubricant temperature of around $150{ }^{\circ} \mathrm{C}$. When preheating the die at $\mathrm{RT}+45^{\circ} \mathrm{C}$ (Fig. 9-a), the fact that $T C_{\text {contact }}$ barely reaches the initial die temperature and remains lower than $T_{s}$ during drawing is attributed to convection loss between the bearing zone and the position of $T C_{\text {contact }}$. Due to these limitations, $T_{\text {tube }}$ was taken as the maximal value between $T_{s}$ and $T_{\text {contact }}$ at the end of drawing. This rough estimate gave a tube temperature of about $60^{\circ} \mathrm{C}$ for RT drawings at $v_{1}$ (Fig. 9-a) and about $127^{\circ} \mathrm{C}$ at $v_{7}$ (Fig. 9-b). For drawings with $T_{\text {die }}=\mathrm{RT}+45^{\circ} \mathrm{C}$ at $v_{1}$, tube temperature is about $87^{\circ} \mathrm{C}$ (Fig. 9-a). $T_{\text {tube }}$ was found to be of little dependence on section reduction and lubricating condition for the tested conditions.

\subsubsection{Typical force evolution}

The forces corresponding to the drawings introduced in Fig. 9-a and b are shown in Fig. 10-a . During drawing, friction between plug and tube tends to drag the plug into the die. In the first tenth of a second $F_{\text {plug }}$ remains nil, as shown in the inset of Fig. 10-a, before the rod starts to hold the plug to compensate the drag force thus maintaining the plug in its equilibrium position. This results in a force overshoot due to plug initial positioning as also measured by Béland (Béland et al., 2011). This overshoot is more pronounced with lower Young's modulus and longer length of the rod (Cook, 1980) and may cause chatter. This overshoot is important since fracture occurs if the drawing force exceeds a critical value. In Fig. 10-a, the overshoot appears to decrease with increasing initial die temperature. This overshoot occurs at ca. $0.3 \mathrm{~s}$, before reaching nominal drawing speed, shown in inset in Fig. 10b. The nominal drawing speeds $v_{1}=40 \mathrm{~mm} / \mathrm{s}$ and $v_{7}=300 \mathrm{~mm} / \mathrm{s}$ are reached after 6.5 and $1.5 \mathrm{~s}$ respectively and are therefore taken to compute the plateau mean forces shown in the next section.

The effect of the lubricating condition on the force evolution is better seen for a tube lubricated with LA + SL on the first $90 \mathrm{~mm}$ on the swaged extremity and with only LA on the rest of its length (Fig. 11-a). The plug force and therefore the drawing force increases suddenly at 


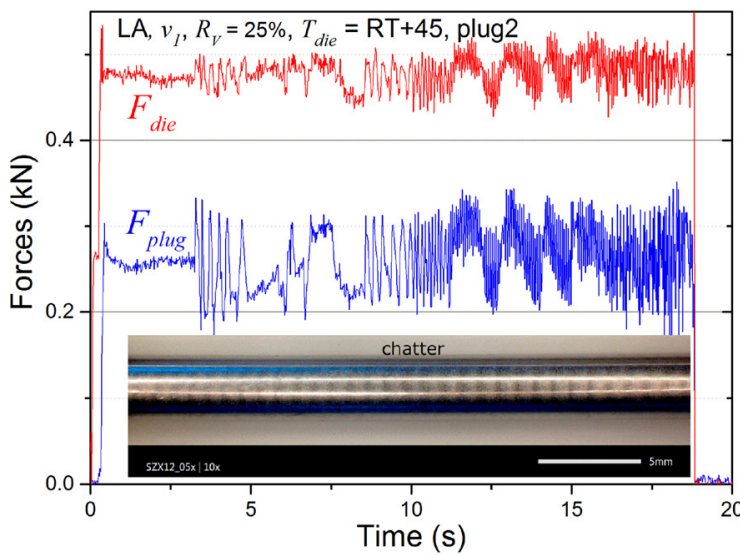

(a)

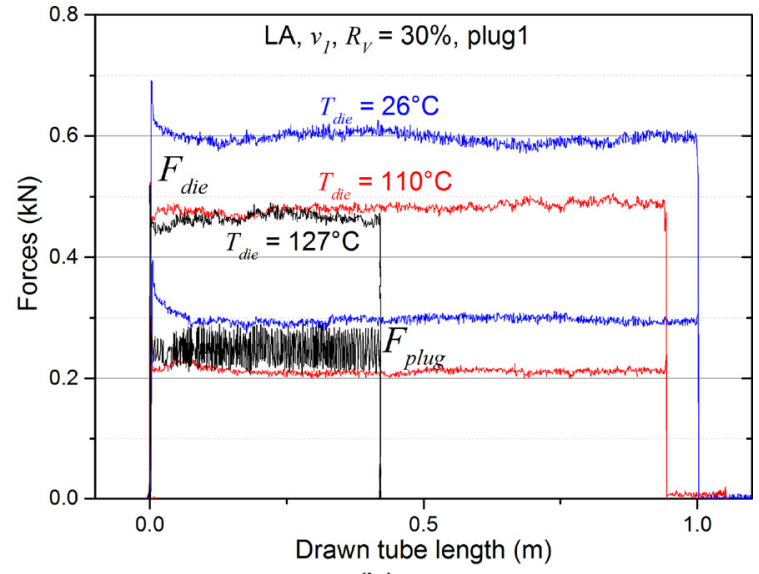

(b)

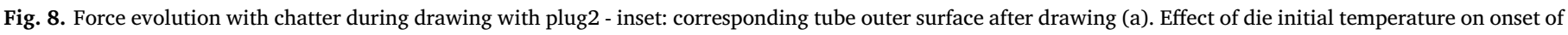
chatter with plug1 (b).

the transition between the tube extremity with LA + SL and the other one with only LA. The solid lubricant reduces the initial overshoot (Fig. 11-b), which is useful to reach high section reductions. In the first $2.5 \mathrm{~s}$ in Fig. 11-b, the fact that $F_{\text {draw }}$ of the tube fully coated with SL is lower than $F_{\text {draw }}$ of the tube partially coated with SL is attributed to the better application of the solid lubricant on the fully coated tube.

\subsubsection{Interrupted drawings}

Forces being dependent on section reduction, a large number of drawings would be required to investigate the whole range of $R_{V}$ for each testing condition. Therefore, the concept of interrupted drawing was introduced to decrease the number of drawings required to produce force - $R_{V}$ diagrams. It consists of interrupting the drawing in order to position the plug deeper into the die, thereby increasing the pass severity thanks to the conical shape of plug2. The results of a tube fixedplug drawing interrupted 3 times are shown exemplarily in Fig. 12-a. After each interruption, the forces feature an overshoot followed by a quasi-plateau. The plateau mean value of each force and the maximal drawing force, $F_{\text {draw peak }}$, are reported as a function of the corresponding section reduction $R_{V}$ (deviation of $\pm 1 \%$ on three samples) in Fig. 12-b. The drawing force overshoot and therefore the drawing limit depends on the yield strength of the material to draw. This is illustrated by the fact that the first peak corresponding to the material hardened by swaging to form the tube tip is higher than the subsequent peaks corresponding to the material hardened by drawing.

Fig. 12-b shows that the drawing and die plateau values increase with increasing section reduction while the plug plateau value is almost

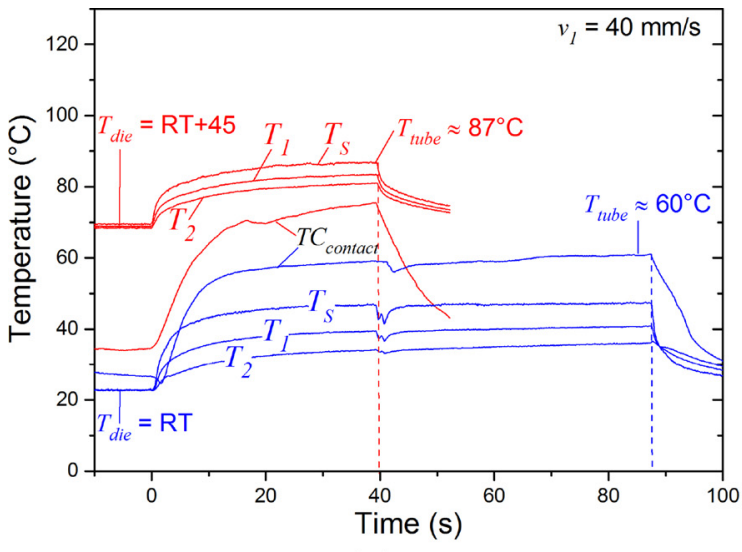

(a) independent of the pass severity. Plug1 gives slightly higher plug forces than plug2 (due to the tube-plug1 contact surface being larger than that of tube-plug2) but slightly lower die forces so that the resulting drawing force is identical to that with plug2. Besides giving the same drawing forces as plug1, plug2 has the advantage of allowing more severe passes (up to fracture) than plug1 (limited to a small range of section reduction around $30 \%)$.

Fig. 12-b gives the maximal achievable section reduction without fracture (ca. 47\%) at $v_{1}$ and $T_{\text {tube }}=60^{\circ} \mathrm{C}$ using LA + SL. Similar force $R_{V}$ diagrams where obtained for drawing conditions given in Table 2.

\subsubsection{Drawing stress - section reduction diagrams}

For comparison, the drawing stress on plateau, $\sigma_{\text {draw }}$, is defined as the drawing force divided by the drawn cross-section, $S_{\text {out }}$, and plotted as a function of section reduction as shown in Fig. 13.

The effect of temperature for drawings at $v_{1}$ using LA + SL is shown in Fig. 13-b: an increase of $T_{\text {tube }}$ from $60^{\circ} \mathrm{C}$ to $87^{\circ} \mathrm{C}$ leads to a decrease of $\sigma_{\text {draw }}$ by ca. $17 \%$ and an increase of the drawing limit from $47 \%$ to $63 \%$. A similar behaviour was found using LB + SL as shown in Fig. 13c where $\sigma_{\text {draw }}$ decreases by $12-24 \%$ and the drawing limit increases from $53 \%$ to $61 \%$ with increasing $T_{\text {die }}$.

The effect of drawing speed using LB $+\mathrm{SL}$ and $T_{\text {die }}=\mathrm{RT}$ is shown in Fig. 13-c: $\sigma_{\text {draw }}$ decreases by $11-16 \%$ when the drawing speed is increased from $v_{1}=40 \mathrm{~mm} / \mathrm{s}$ to $v_{7}=300 \mathrm{~mm} / \mathrm{s}$. To discuss this effect it should be kept in mind that $T_{\text {tube }}$ is around $127^{\circ} \mathrm{C}$ at $v_{7}$. Therefore, considering the thermal effect only, the $\sigma_{\text {draw }}-R_{V}$ curve at $v_{7}$ should be lower than the one at $v_{1}$ with $T_{\text {tube }}=87^{\circ} \mathrm{C}$. This is not the case in

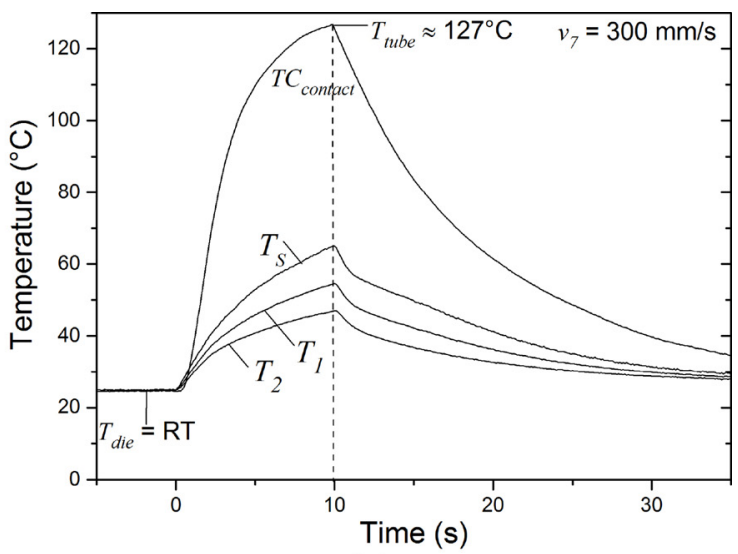

(b)

Fig. 9. Temperature evolution during drawings at $v_{1}$ (a) and $v_{7}$ (b). 


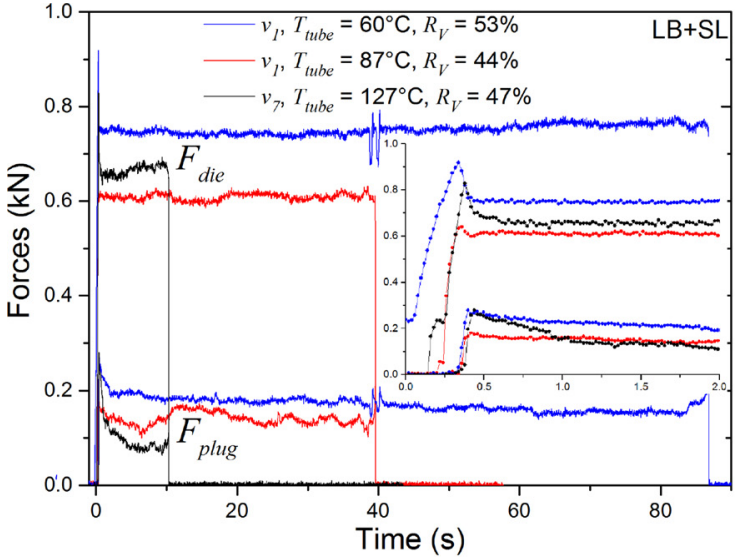

(a)

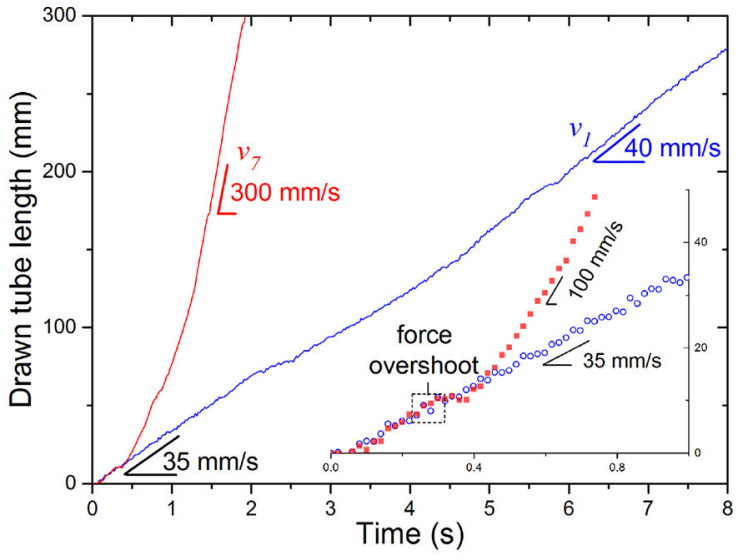

(b)

Fig. 10. Forces evolution during drawing with plug2 introduced in Fig. 9-a and b (a) and drawn tube length evolution for two drawing speeds (b).

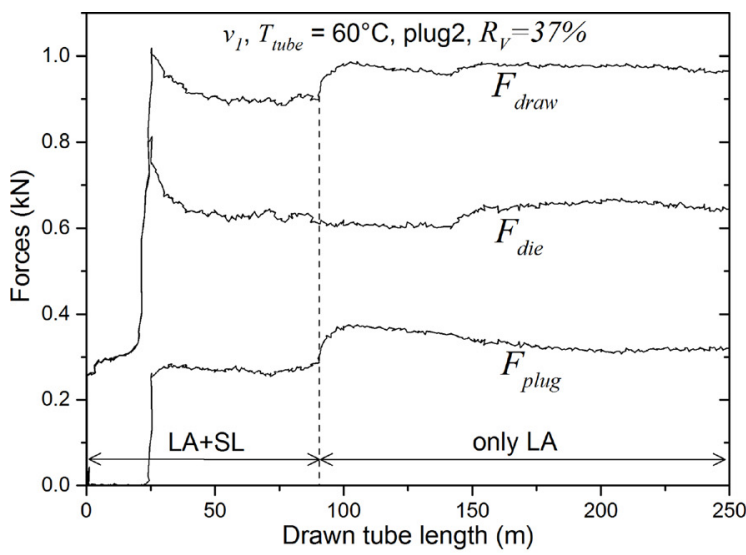

(a)

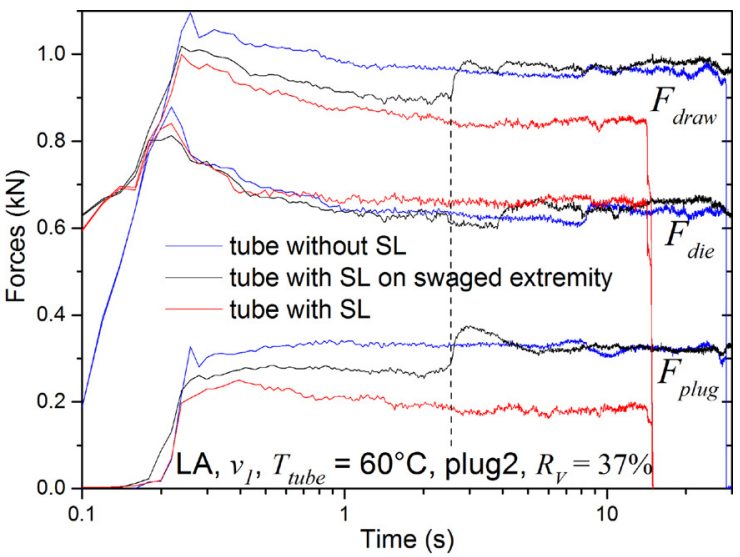

(b)

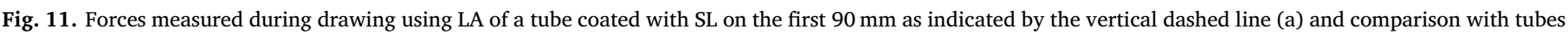
drawn with or without SL (b).

Fig. 13-b where the two curves are almost superimposed. This is attributed to the positive strain-rate sensitivity of the alloy. The higher strain rates reached at $v_{7}$ lead to a higher flow stress and therefore to an increased drawing stress. The same drawing limit was reached at $v_{1}$ and $v_{7}$ due to the fact that for both cases the force overshoot is reached at

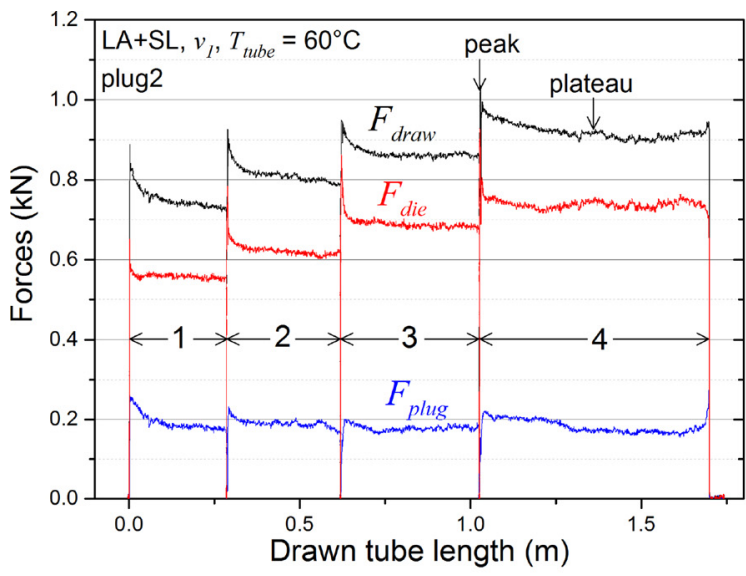

(a)
$35 \mathrm{~mm} / \mathrm{s}$, which is before reaching the nominal drawing speed as shown in Fig. 10-b.

$\sigma_{\text {draw }}$ is lower, implying lubrication is improved, with the use of the solid lubricant as shown in Fig. 13-b where the drawing limit is increased from $37 \%$ (Fig. 13-a) to $47 \%$. The fits of the $\sigma_{\text {draw }}-R_{V}$ curves

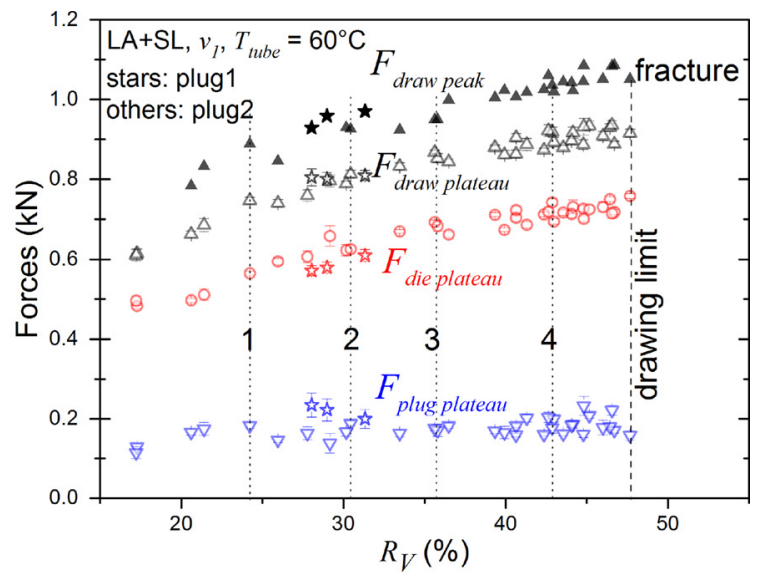

(b)

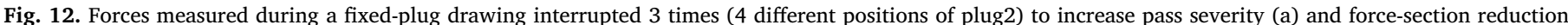
diagram where all points correspond to drawings without fracture (b). 


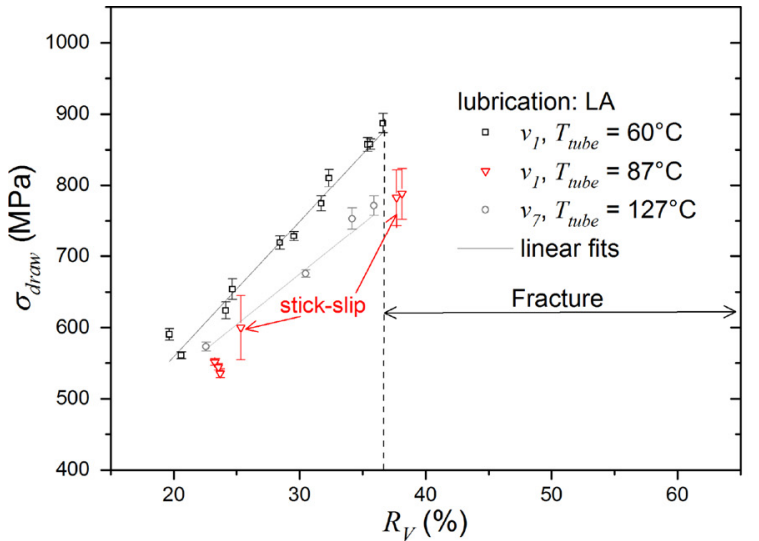

(a)

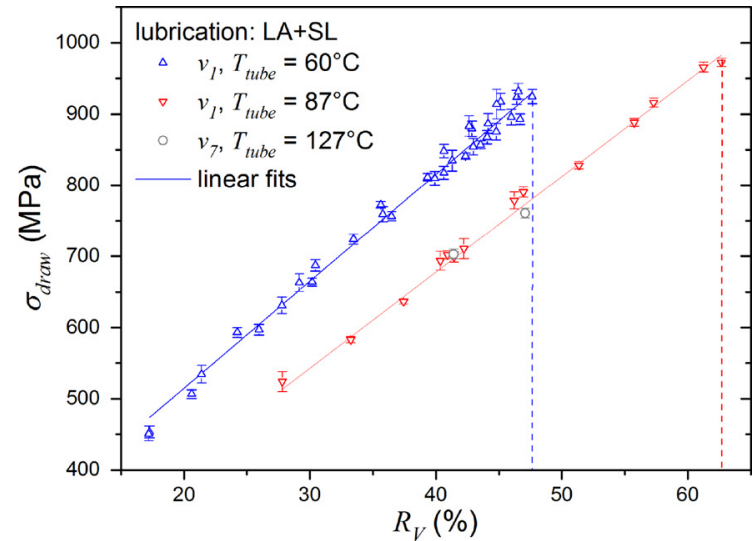

(b)

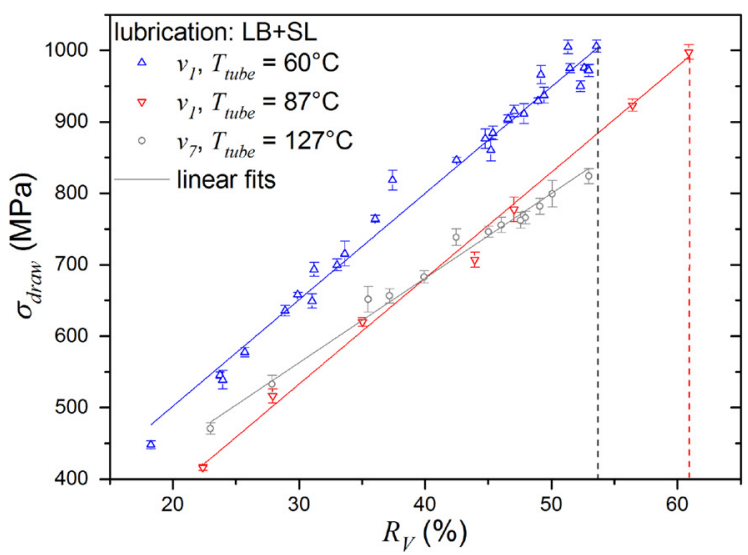

(c)

Fig. 13. $\sigma_{\text {draw }}-R_{V}$ diagrams using plug2 with LA- (a) LA + SL (b) and LB + SL (c). All points correspond to drawings without fracture. The vertical dashed lines indicate the drawing limits. Linear regressions are shown to guide the eye.

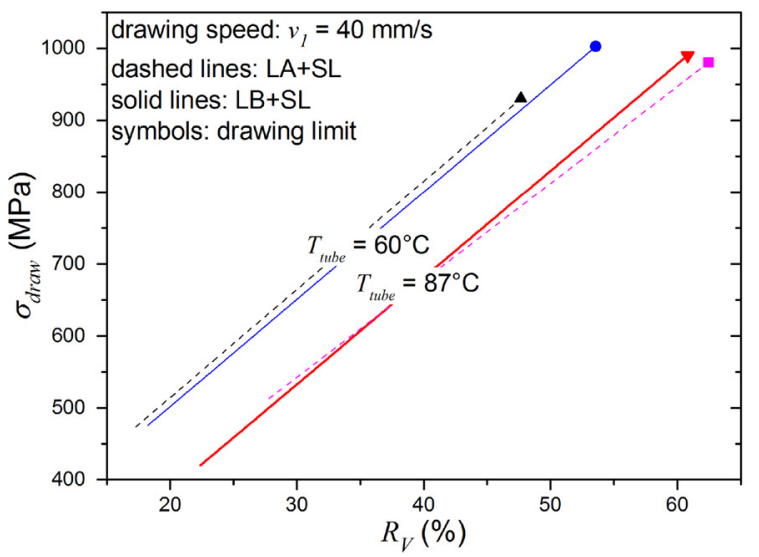

(a)

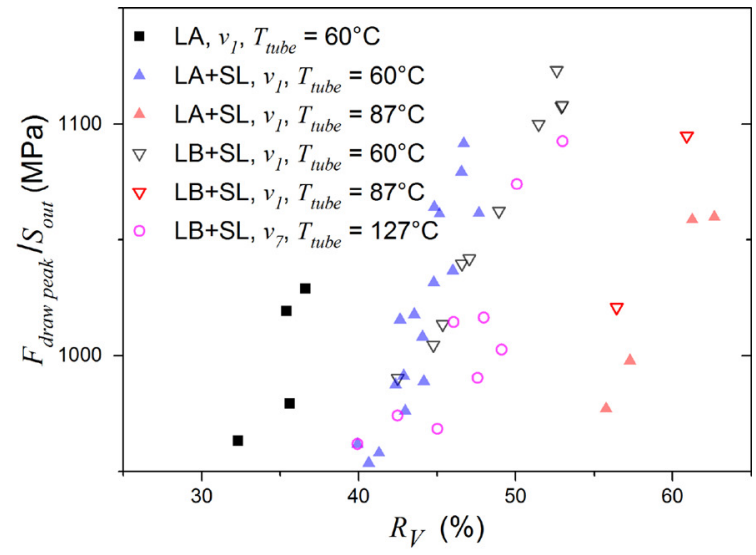

(b)

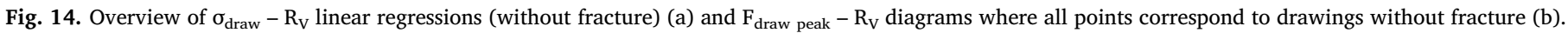

for LA + SL and LB + SL are compared in Fig. 14-a. The curves are almost superimposed for a given tube temperature. At $T_{\text {tube }}=87^{\circ} \mathrm{C}$, for which LA and LB have almost identical viscosities (Fig. 2), the drawing limits with LA + SL and LB + SL indicated by the symbols are almost identical. At $T_{\text {tube }}=60^{\circ} \mathrm{C}$, for which LA and LB have different viscosities, the drawing limit reached with LA + SL is increased with LB + SL. This suggests that the drawing limit increases with decreasing lubricant viscosity, which is consistent with the higher drawing limit obtained with a preheated die. This can be seen in Fig. 14-a and is best understood in Fig. 14-b where $F_{\text {draw peak }}$ is statistically lower with $\mathrm{LB}+\mathrm{SL}$ than with LA $+\mathrm{SL}$ for a given $R_{V}$ at $T_{\text {tube }}=60^{\circ} \mathrm{C}$. For both $\mathrm{LA}+\mathrm{SL}$ and $\mathrm{LB}+\mathrm{LS}$, fracture occurs when the maximal drawing stress during overshoot is around $1100 \mathrm{MPa}$, which is slightly higher than the true stress at fracture measured on full tensile samples (see inset in Fig. 5-a). This difference is to be expected considering the complex loading path during tube fixed-plug drawing. Indeed, the tube undergoes an orthoradial compression in the reduction cone followed by a concomitant radial compression and axial tension in the bearing length. 
Table 3

Overview of the 20 simulations performed with their parameters. $T_{\text {tube }}$ is accounted for through its influence on the tube properties.

\begin{tabular}{llllll}
\hline & & & \multicolumn{2}{l}{ number of simulations } \\
\cline { 5 - 6 } \cline { 5 - 6 }$T_{\text {tube }}\left({ }^{\circ} \mathrm{C}\right)$ & speed & & LA & LA + SL & LB + SL \\
60 & $v_{1}=40 \mathrm{~mm} / \mathrm{s}$ & & 3 & $6+1$ & \\
87 & $v_{7}=300 \mathrm{~mm} / \mathrm{s}$ & & - & - & 5 \\
127 & $v_{1}=40 \mathrm{~mm} / \mathrm{s}$ & & - & 5 &
\end{tabular}

At die exit, the tube is in a stress-state close to uniaxial tension. The onset of ductile fracture depends not only the triaxiality ratio (Cao et al., 2014) but also on the load history as shown by Papasidero et al. (2015) on 2024 aluminium alloy tubular specimens. In general, precompression increases the equivalent plastic strain that can be accumulated before fracture as shown for example by Marcadet and Mohr (2015) on a dual-phase steel.

\subsection{Identification of friction coefficients}

The tube-plug (plug2), $\mu_{p l u g}$, and tube-die, $\mu_{\text {die }}$, friction coefficients were determined by comparing the plug and die plateau forces calculated by the FE model with the measurements. For a given force couple, the two friction coefficients are unique and easily retrieved after 3 iterations. Indeed, it has been checked numerically that the sensitivity of the tube-die friction coefficient to the plug force is about one tenth of the sensitivity to the die force. In other words, $\mu_{\text {die }}$ is primarily dependent on $F_{\text {die }}$. The same findings apply for $\mu_{\text {plug. }}$. A total of $20 \times 3$ simulations with the parameters given in Table 3 were performed and the results in terms of axial forces are shown exemplarily in Fig. 15.

As $\mathrm{LA}+\mathrm{SL}$ and $\mathrm{LB}+\mathrm{SL}$ lubricating conditions lead to similar forces, the identification of the friction coefficients is done for LA + SL (Fig. 15-a) up to $48 \%$ (6 simulations) and for $\mathrm{LB}+\mathrm{SL}$ at $53 \%(+1$ simulation) since LB + SL condition allows more severe passes (Fig. 15b). Please note that the model can be run for $R_{V}$ values higher than the drawing limit determined by measurements as it does not contain any damage model.

The identified friction coefficients decrease with increasing $R_{V}$ as shown in Fig. 16-a for the plug and in Fig. 16-b for the die.

$\mu_{\text {plug }}$ is decreased by the use of the solid lubricant in addition to the liquid one as shown in Fig. 16-a. $\mu_{\text {plug }}$ is further decreased by increasing temperature either by preheating the die or by increasing the drawing speed. The same effects but to a lesser extent are observed for $\mu_{\text {die }}$ with the exception of the solid lubricant, which has almost no effect on $\mu_{\text {die }}$ (Fig. 16-b). The very low obtained values indicate excellent lubrication,

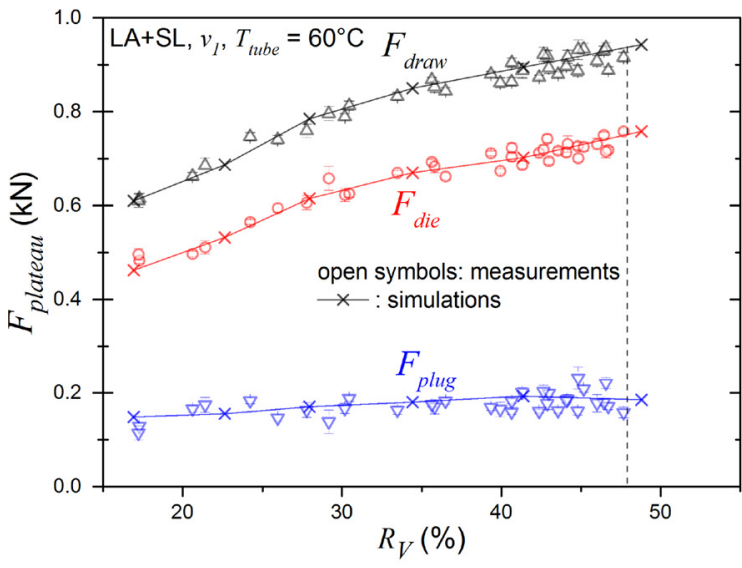

(a) especially on the tube-die surface. Similar values (lower than 0.05) were obtained by Linardon (Linardon et al., 2014) for mandrel drawing. Besides choosing the best lubricant, Neves et al. (2005) showed that friction could be further decreased by promoting pressurised lubrication during tube fixed-plug drawing using two dies assembled within a recipient, which can be sealed.

\subsection{Stribeck friction curves for tube-die contact}

The friction coefficients are plotted as a function of the Stribeck parameter defined as the product of the relative velocity, $V$, and the lubricant dynamic viscosity, $\eta$, divided by the normal force between the two bodies in contact, $F_{N}$, to obtain the Stribeck friction curve (Stribeck, 1902). The FE model gives $V$ (ca. $26 \mathrm{~mm} / \mathrm{s}$ for $v_{1}=40 \mathrm{~mm} / \mathrm{s}$ and ca. $205 \mathrm{~mm} / \mathrm{s}$ for $v_{7}=300 \mathrm{~mm} / \mathrm{s}$ ) and $F_{N}$ for each simulated pass. The difference between the drawing speed and $V$ is due to the tube deformation during drawing and was extracted from the FE modelling.

The viscosity $\eta$ decreases slightly with increasing temperature (Fig. 2) and increases with increasing pressure as shown by McConnell and Lenard (2000) for rolling. The pressure in the lubricant during drawing, which can be up to $1 \mathrm{GPa}$ (Linardon et al., 2014), is difficult to determine and with a few exceptions, seen for instance in Diew et al. (2015), the pressure dependency of $\eta$ is generally not known. Therefore, in this work, $\eta$ is estimated by Reynolds' model (Czichos and Dowson, 1978) based on Navier-Stokes equations for fluid mechanics. It allows calculating the thickness of the lubricant film formed in the contact, $h_{\text {lub }}$, assuming (1) Newtonian fluid, (2) laminar flow, (3) fluid adherence to the walls and (4) incompressible fluid of negligible inertia and weight. Assimilating the die-tube contact to the Reynolds' cylinderplate configuration (Fig. 17-a), $h_{l u b}$ writes (Czichos and Dowson, 1978):

$h_{l u b}=2.45 \times r \times L \times \eta \times V / F_{N}$

where the contact radius $r$ is taken as the mean die curvature radius (ca. $10 \mathrm{~mm}$ in Fig. 17-b) and the contact length $L$ is taken as the die circumference $2 \pi r_{\text {die }}$ (ca. $10 \mathrm{~mm}$ in Fig. 17-b).

The chemical composition profiles measured by XPS on the outer surface of as-drawn tubes is shown in Fig. 18-a and b for LA and $\mathrm{LB}+$ SL lubrication conditions respectively.

The composition profiles obtained on tubes drawn using LA (Fig. 18a) are almost identical with $\left(T_{\text {tube }}=87^{\circ} \mathrm{C}\right)$ or without $\left(T_{\text {tube }}=60^{\circ} \mathrm{C}\right)$ preheating the die. The value of $50 \mathrm{~nm}$ taken for $h_{L A}$ yields a viscosity of $\eta_{L A}=33$ Pa.s using Eq. 4 . Such high viscosity is to be expected due to the high tube-die contact pressure in the order of $800 \mathrm{MPa}$ as found by the FE model.

From Fig. 18-b, the value of $500 \mathrm{~nm}$ is taken as upper bound for

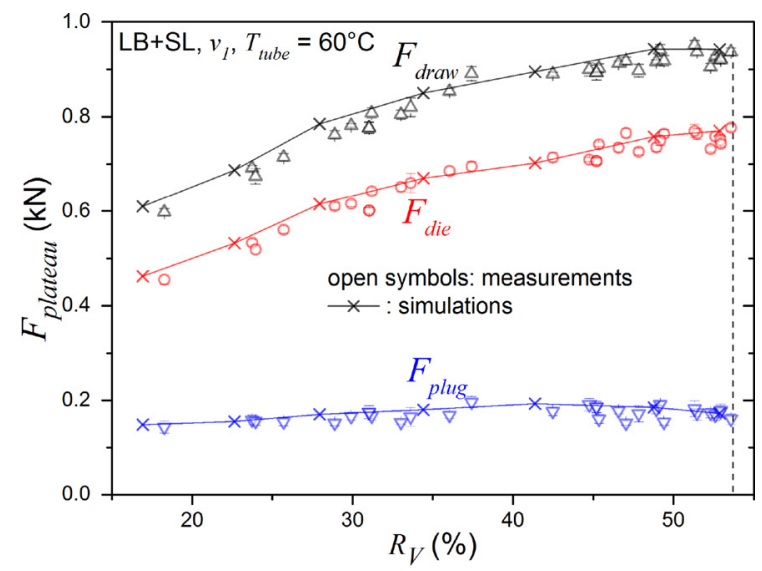

(b)

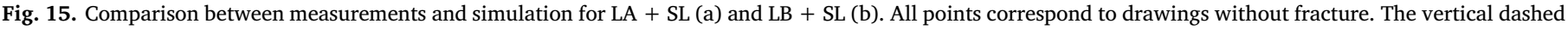
lines indicate the drawing limits. 


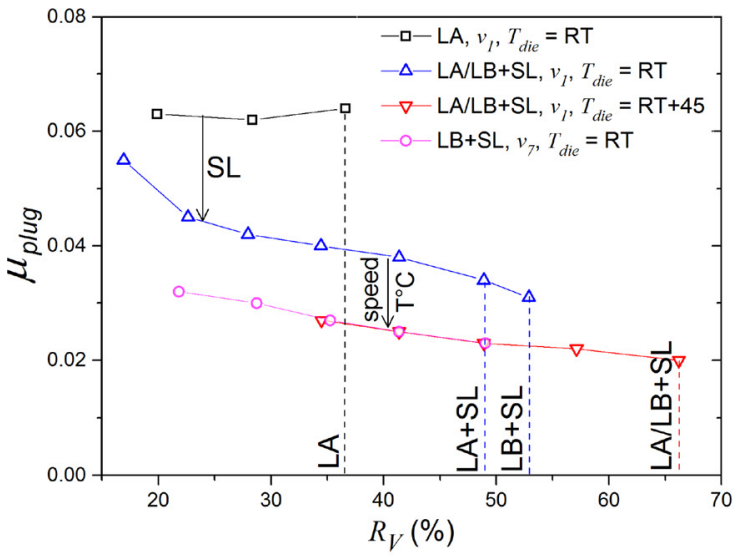

(a)

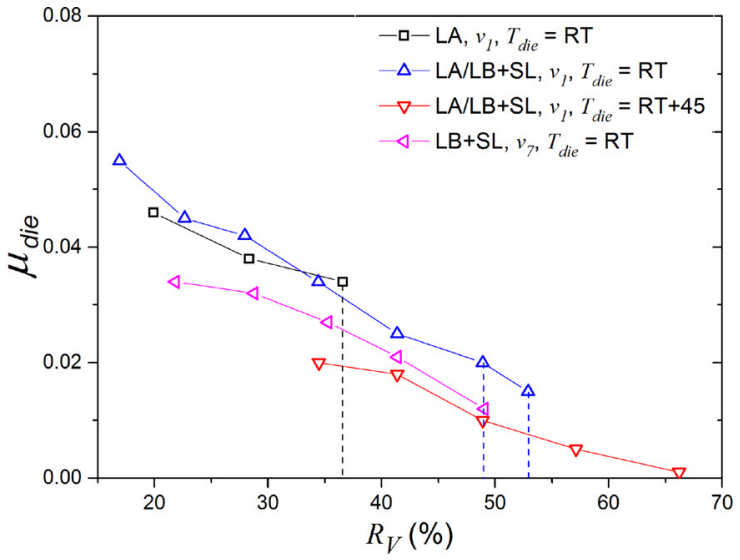

(b)

Fig. 16. Identified friction coefficient between tube and plug2 (a) and tube and die (b). The vertical dashed lines indicate the drawing limits.

$h_{L B+S L}$. This value is comparable with the roughness average on the outer surface of tubes drawn with LB + SL ranging from 0.3 to $0.5 \mu \mathrm{m}$. Using Eq. 4, the value of $\eta_{L B+S L}=280$ Pa.s is found. Such very high viscosity is attributed to the high tube-die contact pressure and the presence of solid lubricant.

The obtained $\eta$ values are applied for the other passes with the same lubricating conditions but different severity to plot the Stribeck friction curve for the tube-die contact (Fig. 19).

$\mu_{\text {die }}$ decreases with decreasing Stribeck parameter in Fig. 19. This indicates that lubrication on the die occurs in the hydrodynamic regime where the tube-die surfaces are completely separated by a lubricant layer. Friction is governed by the rheological behaviour of the lubricant sheared in the high-pressure contact zone. Fig. 19 shows the non-unicity of the Stribeck curve as also found by Diew et al. (2015). The advantage of preheating the die to decrease $\mu_{\text {die }}$ appears clearly. This is in agreement with the work of Velkavrh et al. (2017) who found that friction coefficient decreases with increasing temperature from $50{ }^{\circ} \mathrm{C}$ to $200^{\circ} \mathrm{C}$ for $\mathrm{Zn}$ phosphate + stearate lubricant at high pressure (200-1000 MPa). These results are useful to optimise the pass sequence in the drawing process by choosing the best lubrication and thermal conditions of drawing, which give the lower friction coefficients.

\section{Conclusions}

A simple approach is presented to determine the tube fixed-plug

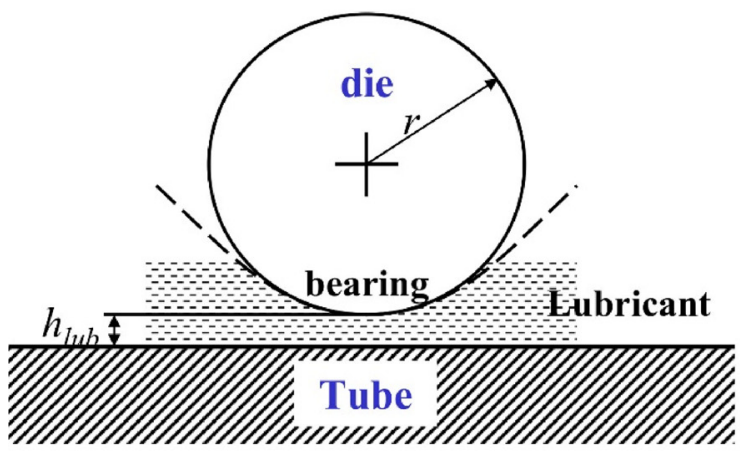

(a) drawing limit with only a few interrupted drawings using a conical plug. The drawing stress - section reduction diagrams obtained for different lubricating conditions and different temperatures reveal the major role of lubricant viscosity and constitute the basis for the determination of friction coefficients. The main findings are summarised below:

- Undesired stick-slip is prevented by improving lubricant feeding of the tube-plug contact through an increased lubricant viscosity, a decreased pass severity and a decreased plug maximal diameter.

- The use of a water-soluble polymer-based solid lubricant together with a lubricating oil decreases the drawing stress thereby increasing the drawing limit.

- The drawing limit is further increased by preheating the die.

- A simple but realistic FE model of drawing accounting for temperature only through its influence on the tube mechanical behaviour allows for rapidly determining the friction coefficients. They are found to decrease with increasing pass severity.

- The Stribeck friction curves associated with lubricant thickness measurements and theoretical predictions from lubrication formalisms show that lubrication in tube drawing can be described using hydrodynamic lubrication concepts.

These results are the basis of the optimisation of the pass sequence by allowing selection of the best lubricating and temperature conditions for increasing the deformation per pass.

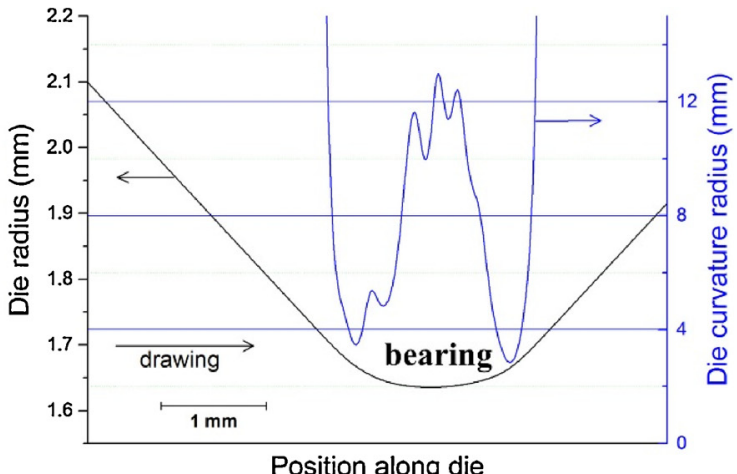

(b)

Fig. 17. Reynolds' theory applied to tube-die contact (a) and corresponding dimensions (b). 


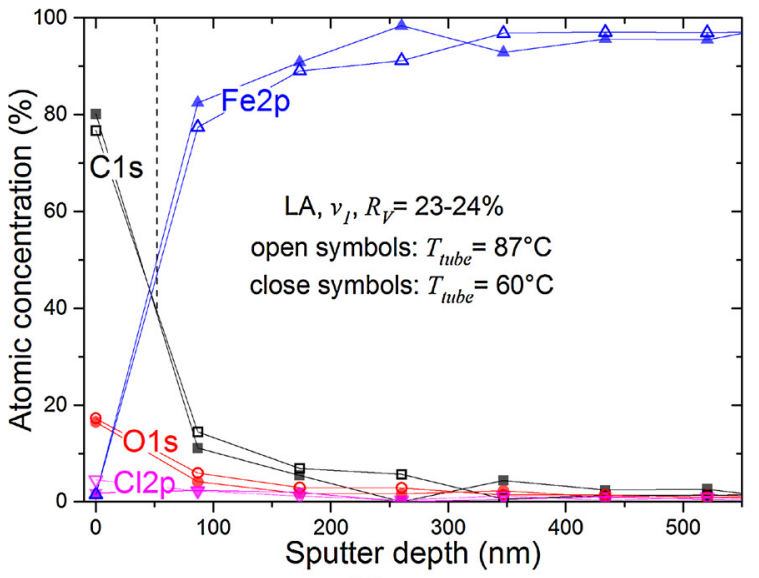

(a)

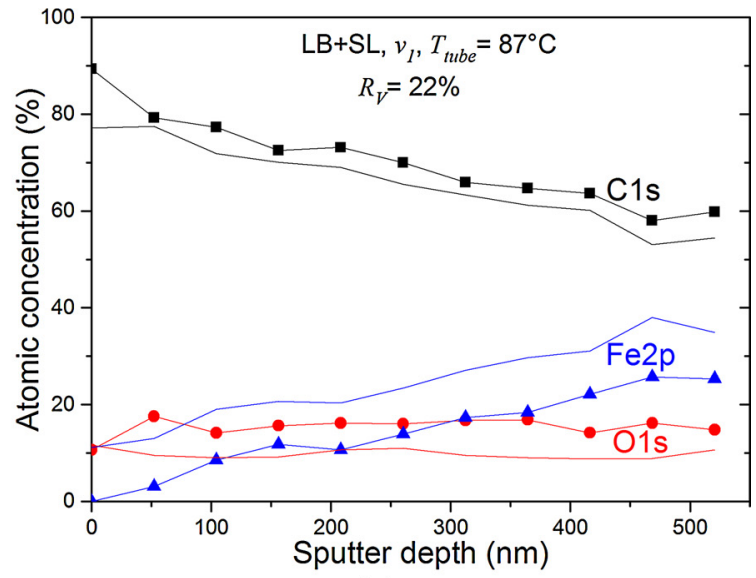

(b)

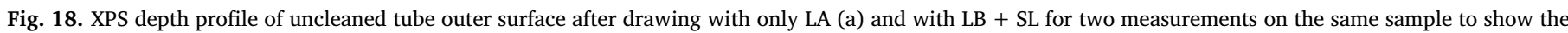
reproducibility (b). The vertical dashed line indicates the estimated lubricant thickness.

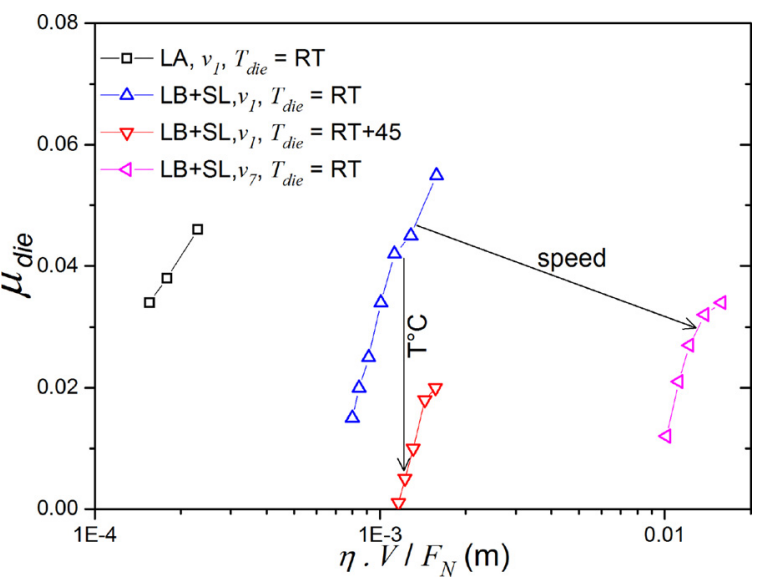

Fig. 19. Comparison of Stribeck friction curves for the tube-die contact.

\section{Acknowledgements}

This work is funded by Innosuisse (http://www.innosuisse.ch/) formerly Commission of Technology and Innovation (CTI) in the frame of the project number 18702.1 PFIW-IW entitled "Tribo-metallurgical integrated approach for drawing ultra thin and smooth walls stainless steel tubes" involving EPF Lausanne, HES-SO//Geneva-Hepia and Swiss-Tube LN Industries SA. The authors are grateful to D. Dietrich (LN Industries) for fruitful discussions, P. Mettraux (EPFL) for XPS measurements and P. Pilvin (Univ. Bretagne Sud) for the provision of SiDoLo.

\section{References}

Albertini, C., Cadoni, E., Solomos, G., 2014. Advances in the Hopkinson bar testing of irradiated/non-irradiated nuclear materials and large specimens. Philos. Trans. R. Soc. Lond. A: Math. Phys. Eng. Sci. 372, 20130197.

Béland, J.F., Fafard, M., Rahem, A., D’Amours, G., Côté, T., 2011. Optimization on the cold drawing process of 6063 aluminium tubes. Appl. Math. Model. 35, 5302-5313.

Bui, Q.H., Bihamta, R., Guillot, M., D’Amours, G., Rahem, A., Fafard, M., 2011. Investigation of the formability limit of aluminium tubes drawn with variable wall thickness. J. Mater. Process. Technol. 211, 402-414.

Bui, Q.H., Pham, X.T., Fafard, M., 2013. Modelling of microstructure effects on the mechanical behavior of aluminium tubes drawn with different reduction areas. Int. J. Plast. 50, 127-145.

Bui-Van, A., Allain, S., Lemoine, X., Bouaziz, O., 2009. An improved physically based behaviour law for ferritic steels and its application to crash modelling. Int. J. Mater. Form. 2, 527-530.

Byun, T., Hashimoto, N., Farrell, K., 2004. Temperature dependence of strain hardening and plastic instability behaviors in austenitic stainless steels. Acta Mater. 52, 3889-3899.
Cao, T.-S., Gachet, J.-M., Montmitonnet, P., Bouchard, P.-O., 2014. A Lode-dependent enhanced Lemaitre model for ductile fracture prediction at low stress triaxiality. Eng. Fract. Mech. 124, 80-96.

Chobaut, N., Carron, D., Arsène, S., Schloth, P., Drezet, J.M., 2015. Quench induced residual stress prediction in heat treatable 7xxx aluminium alloy thick plates using Gleeble interrupted quench tests. J. Mater. Process. Technol. 222, 373-380.

Cook, C., 1980. A model of chatter due to stick-slip in the plug drawing of tubing. J. Appl. Metalwork. 1, 69-75.

Czichos, H., Dowson, D., 1978. Tribology: A Systems Approach to the Science and Technology of Friction, Lubrication and Wear. Published by Elsevier Scientific Publishing Company, PO Box 330. Elsevier, Amsterdam, The Netherlands.

Diew, M., Ernesto, A., Cayer-Barrioz, J., Mazuyer, D., 2015. Stribeck and traction curves under moderate contact pressure: from friction to interfacial rheology. Tribol. Lett. 57,8 .

Fang, G., Ai, W.-j., Leeflang, S., Duszczyk, J., Zhou, J., 2013. Multipass cold drawing of magnesium alloy minitubes for biodegradable vascular stents. Mater. Sci. Eng. C 33, 3481-3488.

Furushima, T., Manabe, K., 2007. Experimental and numerical study on deformation behavior in dieless drawing process of superplastic microtubes. J. Mater. Process. Technol. 191, 59-63.

Haddi, A., Imad, A., Vega, G., 2011. Analysis of temperature and speed effects on the drawing stress for improving the wire drawing process. Mater. Des. 32, 4310-4315.

Hong, S.-G., Lee, S.-B., 2004. The tensile and low-cycle fatigue behavior of cold worked 316L stainless steel: influence of dynamic strain aging. Int. J. Fatigue 26, 899-910.

Karnezis, P., Farrugia, D., 1998. Study of cold tube drawing by finite-element modelling. J. Mater. Process. Technol. 80, 690-694.

Lee, B., Keum, Y., Wagoner, R., 2002. Modeling of the friction caused by lubrication and surface roughness in sheet metal forming. J. Mater. Process. Technol. 130, 60-63.

Lemaitre, J., Chaboche, J.L., 1988. Mécanique des Matériaux Solides, 2e edition ed. Dunod.

Linardon, C., 2014. Precision Tube Drawing for Biomedical Applications : Theoretical, Numerical and Experimental Study, PhD Thesis. Grenoble University.

Linardon, C., Favier, D., Chagnon, G., Gruez, B., 2014. A conical mandrel tube drawing test designed to assess failure criteria. J. Mater. Process. Technol. 214, 347-357.

Marcadet, S.J., Mohr, D., 2015. Effect of compression-tension loading reversal on the strain to fracture of dual phase steel sheets. Int. J. Plast. 72, 21-43.

McConnell, C., Lenard, J., 2000. Friction in cold rolling of a low carbon steel with lubricants. J. Mater. Process. Technol. 99, 86-93.

Neves, F.O., Button, S.T., Caminaga, C., Gentile, F.C., 2005. Numerical and experimental analysis of tube drawing with fixed plug. J. Braz. Soc. Mech. Sci. Eng. 27, 426-431.

Padilha, A.F., Plaut, R.L., Rios, P.R., 2003. Annealing of cold-worked austenitic stainless steels. ISIJ Int. 43, 135-143.

Palengat, M., Chagnon, G., Favier, D., Louche, H., Linardon, C., Plaideau, C., 2013. Cold drawing of 3161 stainless steel thin-walled tubes: experiments and finite element analysis. Int. J. Mech. Sci. 70, 69-78.

Papasidero, J., Doquet, V., Mohr, D., 2015. Ductile fracture of aluminum 2024-T351 under proportional and non-proportional multi-axial loading: bao-wierzbicki results revisited. Int. J. Solids Struct. 69, 459-474.

Pilvin, P., Cailletaud, G., 1994. Identification and inverse problems related to material behaviour. Bui, H.D., Tanaka, M., Bonnet, M., Maigre, H., Luzzato, E., Reynier, M. (Eds.), Proceedings of the Second International Symposium on Inverse Problems 79-86.

Poncin, P., Proft, J., 2004. Stent tubing: understanding the desired attributes. Medical Device Materials: Proceedings of the Materials \& Processes for Medical Devices Conference 253-259.

Stribeck, R., 1902. Die wesentlichen Eigenschaften der Gleit-und Rollenlager [The key qualities of sliding and roller bearings]. Z. Vereines Seutscher Ing. 46, 1432-1437.

Yoshida, K., Furuya, H., 2004. Mandrel drawing and plug drawing of shape-memory-alloy fine tubes used in catheters and stents. J. Mater. Process. Technol. 153, 145-150. 